\title{
The Enzymatic Oxidation of Graphene Oxide
}

\author{
Gregg P. Kotchey ${ }^{1}$, Brett L. Allen ${ }^{1}$, Harindra Vedala ${ }^{1}$, Naveena Yanamala 2,3 , Alexander A. \\ Kapralov $^{2}$, Yulia Y. Tyurina ${ }^{2}$, Judith Klein-Seetharaman ${ }^{3}$, Valerian E. Kagan ${ }^{2}$, and \\ Alexander Star ${ }^{1,}{ }^{*}$ \\ ${ }^{1}$ Department of Chemistry, University of Pittsburgh, Pittsburgh, Pennsylvania, 15260 \\ ${ }^{2}$ Department of Environmental and Occupational Health, University of Pittsburgh, Pittsburgh, \\ Pennsylvania, 15260 \\ ${ }^{3}$ Department of Structural Biology, University of Pittsburgh, Pittsburgh, Pennsylvania, 15260
}

\section{Abstract}

Two-dimensional graphitic carbon is a new material with many emerging applications, and studying its chemical properties is an important goal. Here, we reported a new phenomenon - the enzymatic oxidation of a single layer of graphitic carbon by horseradish peroxidase (HRP). In the presence of low concentrations of hydrogen peroxide $(\sim 40 \mu \mathrm{M})$, HRP catalyzed the oxidation of graphene oxide, which resulted in the formation of holes on its basal plane. During the same period of analysis, HRP failed to oxidize chemically reduced graphene oxide (RGO). The enzymatic oxidation was characterized by Raman, UV-Vis, EPR and FT-IR spectroscopy, TEM, AFM, SDS-PAGE, and GC-MS. Computational docking studies indicated that HRP was preferentially bound to the basal plane rather than the edge for both graphene oxide and RGO. Due to the more dynamic nature of HRP on graphene oxide, the heme active site of HRP was in closer proximity to graphene oxide compared to RGO, thereby facilitating the oxidation of the basal plane of graphene oxide. We also studied the electronic properties of the reduced intermediate product, holey reduced graphene oxide (hRGO), using field-effect transistor (FET) measurements. While RGO exhibited a V-shaped transfer characteristic similar to a single layer of graphene that was attributed to its zero band gap, hRGO demonstrated a p-type semiconducting behavior with a positive shift in the Dirac points. This p-type behavior rendered hRGO, which can be conceptualized as interconnected graphene nanoribbons, as a potentially attractive material for FET sensors.

\section{Keywords}

graphene; oxidation; microscopy; peroxidase; field-effect transistor

Graphene has captured the attention of the scientific community due to its novel electronic properties $^{1,2}$ coupled with its mechanical strength, ${ }^{2,3}$ both of which may make graphene integral in future generations of electronics, batteries, sensors, and composites. $1,2,4^{-6}$ One of the current methods of synthesizing graphene entails exfoliating graphite through

astar@pitt.edu.

Supporting Information Available: Supplemental TEM micrographs for the graphene oxide and RGO experiments (Figure S1); Amplex Red assay for days 1 and 20 of RGO oxidation (Figure S2); electron paramagnetic resonance (EPR) spectroscopy data (Figure S3); AFM images with section analysis of graphene oxide, HRP, and RGO (Figure S4); details of the predicted interaction sites for RGO, graphene oxide, and holey graphene oxide on HRP (Table S1); back gate FET data for hRGO and RGO (Figure S5); and FT-IR and UV-vis spectra of hRGO, RGO, and graphene oxide (Figure S6). This material is available free of charge via the Internet at http://pubs.acs.org. 
oxidation to yield graphite oxide (GO), and this material is sonicated to produce graphene oxide. ${ }^{7}, 8$ Graphene oxide is subsequently reduced either chemically $7^{-}-10$ or thermally $7,11,12$ to produce reduced graphene oxide (RGO).

While the graphene precursor, GO, has been studied for about 170 years, ${ }^{13}$ now there is emerging interest in graphene oxide and RGO.14-18 For example, graphene oxide has been proposed for drug delivery and cellular imaging applications.14 Further, graphene oxide paper formed from interlocking sheets of graphene oxide demonstrated superior strength and stiffness compared to many other papers. ${ }^{15}$ Finally, graphene oxide has been suggested as a simple alternative to poly(3,4-ethylenedioxythiophene)-poly(styrenesulfonate) (PEDOT:PSS), a hole transporting layer and electron blocking layer in organic photovoltaics (OPVs). ${ }^{16} \mathrm{RGO}$, on the other hand, has been employed for both chemical and biological sensing applications.17,18 Given the recent rise in applications for graphene oxide and RGO, it is important to study the chemical properties of these carbon nanomaterials and to develop methods for their remediation to minimize their environmental impact.

Graphene and graphene derivatives such as graphene oxide have been modified for applications through treatment with strong oxidizing and reducing agents, 19 oxidative etching at temperatures greater than $400^{\circ} \mathrm{C}, 20$ etching using lithography, 21 and sonochemical approaches. ${ }^{22}$ Here, we report an entirely new phenomenon; mild enzymatic oxidation resulted in the formation of holey graphene oxide nanostructures as demonstrated by numerous analytical techniques. Computational studies that complemented these results suggested that the molecular mechanisms for oxidation were related to the orientation, dynamics, and binding strength of the enzyme to different graphene sheets. In addition to reporting on the stability of graphene oxide and RGO towards oxidation by peroxidases, we also demonstrated that the enzymatic treatment of this graphitic nanomaterial resulted in alterations of their electronic properties. In particular, we found that holey reduced graphene oxide (hRGO), the reduced form of holey graphene oxide, demonstrated p-type semiconducting behavior, which could make this material desirable for applications involving field-effect transistors (FETs).

\section{RESULTS AND DISCUSSION}

\section{Enzymatic reaction conditions and spectroscopic analysis}

Similar to our previous work where single-walled carbon nanotubes (SWNTs) were degraded via enzymatic catalysis, $23^{-25}$ both graphene oxide and RGO samples were incubated with horseradish peroxidase (HRP) at $\mathrm{pH} 7.0$, room temperature, and low concentrations ( $\sim 40 \mu \mathrm{M}$ final concentration) of hydrogen peroxide $\left(\mathrm{H}_{2} \mathrm{O}_{2}\right)$ that were added daily (Figure 1a). These dispersions, which consisted of either graphene oxide or RGO with HRP, were classified as colloids based on the Tyndall scattering effect (Figure 1b) ${ }^{19}$ In addition, Raman spectroscopy was used to analyze graphene oxide and RGO on days 0,4 , and 20 of incubation with $\mathrm{HRP} / \mathrm{H}_{2} \mathrm{O}_{2}$ (Figure 1c-d), and the ratio of the D band, which measured the presence of disorder in $\mathrm{sp}^{2}$-hybridized carbon systems, to $\mathrm{G}$ band that evaluated stretching of $\mathrm{C}-\mathrm{C}$ bonds in graphitic materials were compared. ${ }^{26}$ For graphene oxide between days 0 and 4, the D:G ratio increased from 1.1:1.0 to 1.6:1.0, and by day 20, both the $\mathrm{D}$ and $\mathrm{G}$ bands disappeared. For RGO, the D:G ratio between day 0 and 4 decreased from 1.2:1.0 to 1.1:1.0, and increased to 1.3:1.0 by day 20. There were two plausible explanations for the increase in the D:G ratio from 1.1:1.0 to 1.6:1.0 between days 0 to 4 of graphene oxide incubation. First, because Raman spectroscopy was performed on different flakes, the variance in the D:G ratio may have been the result of different degrees of graphene oxide oxidation due to the modified Hummers' method. Secondly, there may have been an increase in the number of defect sites as a result of HRP catalyzed oxidation of the graphitic lattice. The $\mathrm{D}$ and $\mathrm{G}$ bands disappeared by day 20 as a result of the complete 
enzymatic oxidation of the graphitic lattice; therefore, Raman spectroscopy provided evidence that graphene oxide underwent oxidation. For RGO samples, Raman data in Figure $1 \mathrm{~d}$ showed an increase in the D:G ratio after graphene oxide was reduced to RGO using hydrazine, similar to previous literature. ${ }^{10}$ The fluctuations observed in the D:G ratio for RGO between days 0,4 , and 20 were attributed to variations in samples since different flakes were examined.

\section{Microscopy}

Transmission electron microscopy (TEM) was utilized to monitor the progression of HRP catalyzed oxidation of graphene oxide over a 20 day period with daily additions of $40 \mu \mathrm{M}$ $\mathrm{H}_{2} \mathrm{O}_{2}$ (final concentration, Figure 2a). Initially at day 0 , flat sheets with dimensions ranging from 0.5 to $1.5 \mu \mathrm{m}$ were observed. After 5 days, graphene oxide sheets began to wrinkle; visible holes were formed in the graphitic lattice of the basal plane by day 8 . The size of the holes increased with time; at day 8 the average hole size was $2.1 \pm 0.6 \mathrm{~nm}$ versus $26.7 \pm 12.8$ $\mathrm{nm}$ at day 10 of the oxidation process (Figure 3). By day 12 as the hole size continued to expand, small flakes of graphene oxide were observed, and the majority of graphene oxide was completely oxidized by day 20 of the experiment (Figure 2a). In contrast, no oxidation was observed by TEM for the graphene oxide controls, $\left(-\mathrm{H}_{2} \mathrm{O}_{2}\right.$, Figure S1a) and (-HRP, Figure S1b). From the TEM micrographs obtained over the twenty-day period of the study, it was concluded that graphene oxide underwent significant oxidation, which resulted in the formation of holes on its basal plane.

The TEM micrographs of graphene oxide at day 8 and 10 of the oxidation process were scrutinized to obtain information regarding the oxidation mechanism. In particular, two parameters were analyzed: the neck width (D) and the hole diameter (d) (Figure 3 insert). Interestingly, as the diameters of the holes increased on average 12 times $(2.1 \pm 0.6 \mathrm{~nm}$ to $26.7 \pm 12.8 \mathrm{~nm})$ from days 8 to 10 , the neck width remained roughly unchanged $(9.4 \pm 7.8 \mathrm{~nm}$ versus $8.9 \pm 6.9 \mathrm{~nm}$ for days 8 and 10, respectively). This implies that enzymatic oxidation cannot produce neck widths (i.e. interconnected nanoribbons) smaller than a certain size. As the enzymatic oxidation reaction proceeded, the necks collapsed, which resulted in an increase in the diameters of the holes on average 12 times from days 8 to 10; the neck width, however, remained roughly unchanged for days 8 and 10 .

As judged by TEM, RGO incubated under identical reaction conditions as graphene oxide, failed to undergo oxidation over the same twenty-day period (Figure 4a, S1c-d). A colorimetric assay performed with Amplex Red, a reagent commonly employed to measure trace $\mathrm{H}_{2} \mathrm{O}_{2}$ concentrations in biological systems, ${ }^{27}$ had a peak for resorufin (the product of HRP catalyzed oxidation of Amplex Red) in the visible region around $570 \mathrm{~nm}$ for a sample containing RGO at both day 1 and day 20 of the oxidation process (Figure S2). The assay revealed that at least a portion of HRP retained enzymatic activity in the presence of RGO; this observation was also confirmed by electron paramagnetic resonance spectroscopy (EPR, Figure S3). Therefore, since there was no visible evidence of enzymatic oxidation for RGO over the twenty-day period of analysis, it appeared that HRP interacted with RGO and graphene oxide differently (vide infra).

Graphene oxide, holey graphene oxide, and RGO were further examined by atomic force microscopy (AFM, Figure 2b, 4b, and S4). AFM section analysis indicated that graphene oxide had a height of $0.61 \mathrm{~nm}$ (Figure S4a); therefore, the exfoliation of GO by sonication successfully produced a single layer of graphene oxide. Since graphene sheets have a height of $0.34 \mathrm{~nm}$, it was not possible for two sheets to be present (i.e. $0.61 \mathrm{~nm}<0.68 \mathrm{~nm}$ ). The presence of covalently attached oxygen functional groups (tertiary alcohols and epoxides) that decorate the basal plane of graphene oxide might be responsible for the added thickness of the graphene oxide flake. In addition, AFM confirmed that HRP binds to graphene oxide 
(Figure 2b). HRP's height was determined by AFM section analysis to be approximately 5 $\mathrm{nm}$ (Figure S4b); ${ }^{24}$ therefore, the height of $5.37 \mathrm{~nm}$ obtained by section analysis in Figure $2 \mathrm{~b}$ (graphene oxide - Day 0 ) indicated that a single layer enzyme was bound to an individual sheet of graphene oxide. Applying the same reasoning, one could conclude that two layers of enzyme existed on graphene oxide to produce a region where the height was $9.81 \mathrm{~nm}$. The height of the holey graphene oxide sheet was $1.10 \mathrm{~nm}$ (a graphene oxide bilayer) with a hole height of $0.01 \mathrm{~nm}$ (Figure 2b, graphene oxide - Day 10). Finally, AFM section analysis indicated that RGO had a height $1.73 \mathrm{~nm}$, which demonstrated that RGO consisted of an aggregation of flakes (Figure S4c). Since the oxygen functional groups on the basal plane were reduced, van der Waals forces dominated between the flakes of RGO resulting in the formation of aggregates. Similar to graphene oxide, AFM confirmed that HRP was bound to RGO during the incubation process; unlike graphene oxide, however, no evidence of oxidation was observed by AFM at day 10 (Figure 4b, RGO - Day 10). With a total height of $7.59 \mathrm{~nm}$, one layer of enzyme was bound to a RGO aggregate that contained between four to seven sheets.

\section{HRP interaction with Graphene Oxide/RGO}

The ability of HRP to bind with sheets of graphene oxide/RGO was confirmed by sodium dodecyl sulfate polyacrylamide gel electrophoresis (SDS-PAGE), followed by silver staining, shown in Figure 5a. Due to its size, both graphene oxide and the highly hydrophobic RGO failed to migrate well during gel electrophoresis; therefore, the majority of the material was retained in the stacking region of the gel. The protein band at $44 \mathrm{kDa}$ corresponded to the literature value for HRP. ${ }^{28}$ While initially all samples contained $1.1 \mathrm{mg}$ of HRP, the quantity of protein that remained post-incubation with RGO was approximately three times less then the quantity of HRP present in other samples, which indicated that HRP was bound more tightly to RGO than graphene oxide. Additionally, the results of gel electrophoresis indicated that minimal auto-oxidation took place during both the tested incubation period and for $40 \mu \mathrm{M}$ levels of $\mathrm{H}_{2} \mathrm{O}_{2}$. In the absence of exogenous oxidizable substrates, monomeric hemoproteins form dimers, trimers, and other oligomers during the activation of their peroxidase. This stems from the recombination of protein-derived (likely, tyrosyl) radicals generated as reaction intermediates ${ }^{29-} 31$ and results in the formation of covalent cross-links that are non-dissociable in SDS. Thus if HRP oligomers were formed in the reaction, they should have been detectable in the SDS gel. The lack of HRP oligomers indicated that $\mathrm{H}_{2} \mathrm{O}_{2}$-dependent cross-linking of the enzyme did not take place, and the oxidizing potential of the enzyme was directed towards graphene oxide/RGO oxidation.

\section{Molecular Modeling Studies}

Employing AutoDock Vina software, ${ }^{32}$ molecular docking studies were performed to identify the manner by which HRP was bound to RGO and graphene oxide. Docking of RGO to HRP indicated that there existed only one binding site on HRP where RGO can bind (Figure 4c, Table S1). The closest distance to the heme active site from RGO was $11.5 \AA$. The results for graphene oxide, on the other hand, indicated two different binding sites for graphene oxide on HRP. The first binding site was similar to the RGO binding site with participation of the additional residues Ala86, Glu88, Ser89, Pro92, and Lue299. The heme active site was predicted to be $12.8 \AA$ away from the graphene oxide surface (Table S1). In comparison to the first binding site, the heme active site in the case of second binding site was predicted to be $8.7 \AA$ away from the surface of graphene oxide (Figure 2c, Table S1). When a hole was introduced into the graphene oxide sheet, we predicted only one binding site that consisted of HRP residues similar to that of the second binding site described for graphene oxide above (Figure 2c). The overall predicted binding energy was $-26.7 \mathrm{kcal}$ $\mathrm{mol}^{-1}$ for RGO; the two binding sites on graphene oxide had binding energies of $-24.8 \mathrm{kcal}$ $\mathrm{mol}^{-1}$ and $-22.4 \mathrm{kcal} \mathrm{mol}^{-1}$, respectively. These results indicated that HRP may bind more 
tightly to RGO than to graphene oxide. This was consistent with the gel electrophoresis data, which indicated that two-thirds of the incubated HRP was bound to RGO and retained in the well. The difference in binding of HRP to graphene oxide as compared to RGO may be responsible for the observed oxidation. These findings are also in line with our previous observation of HRP binding to oxidized versus non-oxidized SWNTs, where we also observed a preference of the enzyme's active site to be in closer proximity of the binding interface in oxidized material than in non-oxidized material. Finally, it was observed experimentally that holes formed preferentially on the basal plane, which indicated that the enzyme was more favorably bound to and oxidized the planer portion of graphene oxide instead of the edge. This observation was consistent with the docking results that only identified favorable binding poses on the plane. Thus, it appeared that the edge failed to provide sufficient surface area for stabilization of the graphene-HRP interaction through hydrophobic contacts.

In summary, the molecular modeling studies suggest that the presence of epoxy- and hydroxyl groups in the basal plane and the flexibility of the oxidized graphene sheet may be responsible for the preferential enzymatic oxidation of graphene oxide and holey graphene oxide versus RGO by HRP.

\section{Molecular mechanisms of oxidation}

No visible evidence of oxidation as determined by TEM was observed for RGO over the twenty-day period of analysis. Both the Amplex Red assay and the EPR data confirmed that the enzyme, HRP, remained active in the presence of RGO; therefore, another mechanism was responsible for the lack of visible oxidation. Based on our prior work with oxidized SWNT degradation ${ }^{23-25}$ and the results obtained from the computational study, a potential mechanism for graphene oxide/RGO oxidation was elucidated. Since the binding energy was greater for RGO than graphene oxide, it was possible that the oxygen groups on graphene oxide allowed the enzyme to be more dynamic, which brought the heme site in close proximity of graphene oxide. Conversely, as a result of tighter binding between RGO and HRP, the dynamic motion of the enzyme was retarded. Therefore, the heme active site of HRP was not in close proximity of the graphene lattice, which was necessary for oxidation to occur. Initially, HRP was inactive, where the heme peroxidase was in the ferric oxidation state. In the presence of hydrogen peroxide $\left(\mathrm{H}_{2} \mathrm{O}_{2}\right)$, the heme active site underwent a protein-assisted conversion to a ferryl oxo iron $\left(\mathrm{Fe}^{4+}=\mathrm{O}\right)$ porphyrin $\pi$ cation radical known as Compound I. ${ }^{33}$ Compound I was reduced back to the ferric state in two sequential, one-electron transfer steps. In the first step, the transient intermediate, Compound II, was produced; during this process, the porphyrin $\pi$ cation radical was reduced while graphene oxide was oxidized. Graphene oxide underwent further oxidation when the ferryl oxo iron $\left(\mathrm{Fe}^{4+}=\mathrm{O}\right)$ was subsequently reduced to the ferric state. During this process, the $\sigma$ carbon-carbon bond of the tertiary hydroxyl and epoxide groups that were formed during the initial oxidization of graphite by $\mathrm{KMnO}_{4}$ and $\mathrm{H}_{2} \mathrm{SO}_{4}$ were cleaved. This was consistent with the literature, where it was demonstrated that peroxidases have the ability to catalyze both epoxidation and cleavage of carbon-carbon bonds in the presence of $\mathrm{H}_{2} \mathrm{O}_{2} \cdot{ }^{34}$, 35

\section{Oxidation product analysis}

While identification of the intermediate products of graphene oxide oxidation is ongoing, product analysis in the sample headspace utilizing gas chromatography - mass spectrometry (GC-MS) indicated that $\mathrm{CO}_{2}$ was the final product of complete enzymatic catalyzed oxidation. Sample headspace of sealed vials in which HRP was incubated with either graphene oxide (Figure 5b) or RGO (Figure 5c) was extracted, and the concentration of $\mathrm{CO}_{2}$ was determined. By day 10 , the concentration of $\mathrm{CO}_{2}$ increased by $65 \%$ for graphene oxide 
(Figure 5b) and 2\% for RGO (Figure 5c) over ambient; whereas the controls for graphene oxide (-HRP, $-\mathrm{H}_{2} \mathrm{O}_{2}$, and -graphene oxide) indicated only a $2-4 \%$ increase in relative $\mathrm{CO}_{2}$ levels at day 10 (Figure $5 b$ ). With over thirty times the amount of $\mathrm{CO}_{2}$ produced for graphene oxide oxidation compared to the RGO control, the Raman and TEM results, which indicated that graphene oxide underwent HRP catalyzed oxidation, appeared to be substantiated.

\section{Enzymatic Kinetics}

Amplex Red was utilized to monitor the concentration of the substrate, $\mathrm{H}_{2} \mathrm{O}_{2}$, as a function of time to yield enzyme kinetics. HRP incubated with graphene oxide and $\mathrm{H}_{2} \mathrm{O}_{2}$ demonstrated that $97 \%$ of the substrate was consumed within 30 minutes (Figure 5d). It should be emphasized here that in all above experiments $\mathrm{H}_{2} \mathrm{O}_{2}$ was added on a daily basis to facilitate thorough characterization of the oxidation products. Taking into account the enzymatic kinetic data, we conducted additional experiments, where $\mathrm{H}_{2} \mathrm{O}_{2}$ was added every 30 minutes. For the resulting data, holes were observed in the basal plane of graphene oxide after 4.5 hours (Figure S1e). These results proved difficult to reproduce, however, due to the quick rate of enzymatic oxidation once holes were formed, rendering most of the graphene oxide "over-oxidized" (Figure S1f). Attempts to shorten the total oxidation time by 15 minutes (i.e. for a total oxidation time of 4.25 hours) yielded pristine graphene oxide sheets; therefore, there existed a narrow window, where hole formation occurred. Consequently, with respect to reproducibly generating holey graphene oxide, the multi-day approach appeared advantageous, and holey graphene oxide has been produced several times utilizing this technique.

\section{Electronic properties of holey reduced graphene oxide (hRGO)}

Creating holes in graphene is important for fine-tuning its electronic properties. As a result of its zero bandgap, graphene is a semimetal.36, ${ }^{37}$ This property limits graphene's utility in some electronic applications such as room temperature field-effect transistors (FETs), which require semiconducting materials. To overcome this limitation, theoretical work has predicted that quantum confinement and edge effects would produce semiconducting properties at room temperature in graphene sheets that have widths less than $10 \mathrm{~nm}$; an active area of graphene research involves the fabrication of these quasi-one-dimensional structures referred to as graphene nanoribbons (GNRs) ${ }^{38-} 40$ Block copolymer lithography, 41,42 laser induced photochemical reactions,${ }^{43}$ Joule heating, ${ }^{44}$ oxidative etching at temperatures greater than $400^{\circ} \mathrm{C},{ }^{20}$ and two-dimensional polymer synthesis ${ }^{45}$ have been employed to create nanometer sized holes on individual sheets of graphene. As a sheet of perforated graphene can be conceptualized as interconnected nanoribbons, the creation of holes in the basal plane of graphene opens its bandgap to yield a semiconducting nanomaterial.

To test if the sideproduct of enzymatic oxidation has unique electronic properties, holey graphene oxide that was formed after 8 days of oxidation was reduced with hydrazine to yield hRGO flakes (Figure S1g), and this material demonstrated electrical conductivity. Both liquid-gated and back-gated FET measurements were implemented on RGO and hRGO (Figure 6a and S5a-b). For both of the measurement techniques, similar electronic transport characteristics were observed with the liquid gate measurement demonstrating more effective tuning of charge carriers. ${ }^{46} \mathrm{RGO}$ exhibited a V-shaped transfer characteristic (Figure 6a) similar to a single layer of graphene, which can be attributed to the zero band gap of graphene. ${ }^{47-49}$ In comparison, hRGO exhibited a decrease in conductance with a ptype behavior and a positive shift in the Dirac points (Figure 6a). The comparison of transconductance $\left(\Delta \mathrm{I} / \Delta \mathrm{V}_{\mathrm{g}}\right)$ values for the $\mathrm{n}$ and $\mathrm{p}$ regions (Figure $6 \mathrm{~b}$ ) obtained from 12 
different RGO and hRGO FET devices (6 devices each) confirmed the repeatability of the enhanced p-type semiconducting behavior of hRGO compared to RGO.

The observed p-type behavior for hRGO samples can be attributed to the presence of holes in the basal plane of the graphene nanomaterial, which resulted in the opening of the band gap as a consequence of lateral quantum confinement ${ }^{38-40}$ and the presence of additional oxygen-containing functional moieties (i.e. carboxylic acids, lactols, quinines, hydroquinones, etc.) around the holes that were introduced during the enzymatic oxidation process. These data were in accordance with recent reports on nanoperforated graphene. ${ }^{41}$, 42

\section{CONCLUSION}

In this work, we demonstrated that HRP catalyzed the oxidation of graphene oxide that resulted in the formation of holes in the basal plane of this nanomaterial; over the same period of time, HRP failed to catalyze the oxidation of RGO. These observations were consistent with the computational findings, which indicated that the heme active site of HRP was in closer proximity, and the enzyme itself was more dynamic when bound to GO compared to RGO. This made graphene oxide more susceptible to carbon-carbon bond cleavage. With proposals for graphene oxide to be implemented in applications with an environmental impact, ${ }^{50}$ the described enzymatic oxidation may be an attractive method for the bioremediation of graphene oxide. In addition to the environmental perspective, we discovered that enzymatic oxidation of graphene oxide produced holey graphene nanostructures, which upon reduction, demonstrated p-type semiconducting behavior. This material may have potential applications in electronic and sensor devices.

\section{METHODS}

\section{Materials}

Graphite flakes, lyophilized HRP type VI, PBS, hydrazine hydrate (50 wt $\%$ ), and $30 \% \mathrm{H}_{2} \mathrm{O}_{2}$ were purchased from Sigma Aldrich. Amplex Red was purchased from Molecular Probes, Invitrogen, and the SilverSNAP stain kit was acquired from Thermo Scientific.

\section{Preparation of Graphene Oxide and RGO}

Graphite oxide was prepared utilizing a modified Hummers' method on graphite flakes that underwent a preoxidation step. ${ }^{51}$ Graphene oxide $(\sim 0.125 \mathrm{wt} \%)$ was formed from graphite oxide that was diluted 1:4 with double distilled water and exfoliated for 30 minutes by ultrasonication followed by 30 minutes of centrifugation at 3400 r.p.m to remove unexfoliated graphite oxide. Atomic force microscopy (AFM), Fourier transform infrared spectroscopy (FT-IR), ultraviolet-visible spectroscopy (UV-vis), and transmission electron microscopy (TEM) were employed to characterize the exfoliated graphene oxide. Graphene oxide had a sheet height of $0.61 \mathrm{~nm}$, which was determined by section analysis and confirmed that a single layer of graphene oxide was present (Figure S4a). Additionally, as evident by the FT-IR spectrum in Figure S6a, major peaks appeared around $3400 \mathrm{~cm}^{-1}$, $1700 \mathrm{~cm}^{-1}$, and $1000 \mathrm{~cm}^{-1}$, which were attributed to $\mathrm{O}-\mathrm{H}, \mathrm{C}=\mathrm{O}$, and $\mathrm{C}-\mathrm{O}$ stretching vibrations, respectively. Moreover, Figure 2a depicted a single sheet of graphene oxide as captured by TEM.

Graphene oxide was reduced to form RGO employing hydrazine hydrate, and RGO was dispersed in water with ammonium hydroxide at a $\mathrm{pH}$ around 10 following a published procedure. ${ }^{19}$ A mixture containing $5.0 \mathrm{~mL}$ of $0.125 \mathrm{wt} \%$ graphene oxide, $4.8 \mathrm{~mL}$ of double distilled water, $200 \mu \mathrm{L}$ of hydrazine hydrate (50 wt \%), and $35 \mu \mathrm{L}$ of $\mathrm{NH}_{4} \mathrm{OH}(28 \mathrm{wt} \%$ ) was stirred for 5 minutes and heated at $95{ }^{\circ} \mathrm{C}$ for 1 hour. The suspension containing RGO was 
subsequently dialyzed against distilled water to remove hydrazine and $\mathrm{NH}_{4} \mathrm{OH}$. $\mathrm{RGO}$ had a sheet height of $1.73 \mathrm{~nm}$, which was determined by section analysis and confirmed that between three to five layers of RGO was present (Figure S4c). The FT-IR spectrum for RGO (Figure S6a) depicted a reduction in the O-H stretch around $3400 \mathrm{~cm}^{-1}$, and carbonyl groups appeared around $1700 \mathrm{~cm}^{-1}$. Figure $4 \mathrm{a}$ and Figure S1c-d depicted the TEM micrograph of RGO, and the UV-vis spectrum of RGO displayed a shoulder around $327 \mathrm{~nm}$ (Figure S6b).

\section{Incubation with $\mathrm{HRP}$ and $\mathrm{H}_{2} \mathrm{O}_{2}$}

Three vials were prepared by adding $2.0 \mathrm{~mL}$ of the $0.125 \mathrm{w} / \mathrm{v}$ graphene oxide dispersed in double distilled water. Lyophilized HRP type VI was solubilized in $1 \times$ phosphate buffered saline (PBS) $(11.9 \mathrm{mM}$ phosphates, $137 \mathrm{mM} \mathrm{NaCl}$, and $2.7 \mathrm{mM} \mathrm{KCl})$ at $0.390 \mathrm{mg} \mathrm{mL}^{-1}$ and added to two of the vials containing graphene oxide at a volume of $4.0 \mathrm{~mL}$. This created two vials with a total volume of $6.0 \mathrm{~mL}$ (active and control $\mathrm{I},-\mathrm{H}_{2} \mathrm{O}_{2}$ ) and one with a total volume of $2.0 \mathrm{~mL}$ (control II, $-\mathrm{HRP}$ ). Next, $3.5 \mathrm{~mL}, 4.0 \mathrm{~mL}$, and $7.5 \mathrm{~mL}$ of $1 \times \mathrm{PBS}$ were added to active, control I, and control II, respectively, for a total volume of $9.5 \mathrm{~mL}, 10.0 \mathrm{~mL}$ and $9.5 \mathrm{~mL}$. All vials were then sealed with a septum and wrapped with parafilm to create an airtight seal. The identical procedure was followed to prepare three vials for RGO. An additional control III vial (-graphene oxide) was created by adding $4.0 \mathrm{~mL}$ of $\mathrm{HRP}$ and 5.5 $\mathrm{mL}$ of $1 \times$ PBS. A sample of $0.5 \mathrm{~mL}$ of $800 \mu \mathrm{M} \mathrm{H}_{2} \mathrm{O}_{2}$ was added by needle through the septum to the active, control II, and control III vials; this started the oxidation reaction. Daily additions of $4 \mu \mathrm{L}$ of $0.1 \mathrm{M} \mathrm{H}_{2} \mathrm{O}_{2}$ were added to the active, control II, and control III vials; this was continued on a daily basis for twenty days.

\section{Preparation of Holey Reduced Graphene Oxide (hRGO)}

A sample of holey graphene oxide subjected to 8 days of oxidation was reduced to form hRGO employing hydrazine hydrate in an aqueous suspension containing ammonium hydroxide at a $\mathrm{pH}$ around 10 following a published procedure (Figure S1g). ${ }^{19} \mathrm{~A}$ mixture containing $5.0 \mathrm{~mL}$ of $0.125 \mathrm{wt} \%$ holey graphene oxide, $4.8 \mathrm{~mL}$ of double distilled water, $200 \mu \mathrm{L}$ of hydrazine hydrate (50 wt \%), and $35 \mu \mathrm{L}$ of $\mathrm{NH}_{4} \mathrm{OH}(28 \mathrm{wt} \%$ ) was stirred for 5 minutes and heated at $95{ }^{\circ} \mathrm{C}$ for 1 hour. The suspension containing hRGO was subsequently dialyzed against distilled water with $0.5 \% \mathrm{NH}_{4} \mathrm{OH}$ to remove hydrazine. The FT-IR spectrum for RGO (Figure S6a) depicted a reduction in the O-H stretch around $3400 \mathrm{~cm}^{-1}$, and carbonyl groups appeared around $1700 \mathrm{~cm}^{-1}$. Moreover, the UV-vis spectrum demonstrated a well-defined peak around $327 \mathrm{~nm}$ (Figure S6b).

\section{Raman Spectroscopy}

Samples were prepared by drop-casting approximately $20 \mu \mathrm{L}$ of graphene oxide or RGO at days 0,4 , or 20 on a quartz microscope slide and drying. All spectra were collected on a Renishaw inVia Raman microscope using an excitation wavelength of $633 \mathrm{~nm}$. Samples were scanned from $1000-3000 \mathrm{~cm}^{-1}$ to visualize the D and G bands. Spectra were collected with a 15 second exposure time and averaged across 5 scans per location; a total of 10 locations were selected per sample.

\section{Transmission Electron Microscopy}

Samples in PBS suspension were first centrifuged at 3400 r.p.m. for 30 minutes and decanted of supernatant in order to effectively remove salt contributions from the buffer. The sample was re-suspended into approximately $1 \mathrm{~mL}$ of double distilled $\mathrm{H}_{2} \mathrm{O}$ by sonication for one minute. One drop of the suspended sample was placed on a lacey carbon grid (Pacific-Grid Tech) and allowed to dry in ambient conditions for 2 hours prior to TEM imaging (FEI Morgagni, $80 \mathrm{keV}$ ). 


\section{Atomic Force Microscopy (AFM)}

A Multimode scanning probe microscope (Veeco) was utilized in tapping mode for height, phase, and sectional analysis. Sample preparation was performed on freshly cleaved mica that was treated with approximately $20 \mu \mathrm{L}$ of $0.1 \%(\mathrm{w} / \mathrm{w})$ poly $-\mathrm{L}-$ Lysine (aq) through spin-coating at 1,400 r.p.m. Approximately $10 \mu \mathrm{L}$ of sample (aq) was spin-coated at 1,400 r.p.m. and allowed to dry in ambient for 45 minutes prior to imaging. Using a "supersharp" Si probe (tip radius $<5 \mathrm{~nm}$, AppNano), tapping mode was performed at a drive frequency of $182.316 \mathrm{~Hz}$, an amplitude set point of $0.2465 \mathrm{~V}$, and a drive amplitude of $216 \mathrm{mV}$. Images were initially scanned in a $13.1 \mu \mathrm{m}$ area prior to magnification of relevant areas. Postimaging processing included section analysis for quantifying cross-sectional heights of samples.

\section{Monitoring HRP Activity with Amplex Red}

Amplex Red (Molecular Probes, Invitrogen) was employed to test HRP activity. A $10 \mathrm{mM}$ stock solution of Amplex Red was prepared by dissolving the reagent in DMSO. To a 250 $\mu \mathrm{L}$ aliquot of sample being tested for enzymatic activity, $234 \mu \mathrm{L}$ of $1 \times \mathrm{PBS}, 15 \mu \mathrm{L}$ of 800 $\mu \mathrm{M} \mathrm{H}_{2} \mathrm{O}_{2}$ and $1 \mu \mathrm{L}$ of $10 \mathrm{mM}$ Amplex Red were added. After gentle mixing, the UV-Vis spectrum of the sample was taken with $1 \times \mathrm{PBS}$ used as the background.

\section{UV-vis-NIR Spectroscopy}

Aqueous samples $(150 \mu \mathrm{L})$ were analyzed using a Lambda 900 spectrophotometer (Perkin Elmer) and $0.20 \mathrm{~mL}$ quartz cuvettes (Path length: $1 \mathrm{~cm}$, World Precision Instruments, Inc.). The samples for the Amplex Red study were scanned from $300-800 \mathrm{~nm}$. All samples were used without any further treatment or purification.

\section{Electron Paramagnetic Resonance Spectroscopy}

To each sample containing HRP $(0.35 \mu \mathrm{M})$ and etoposide $(200 \mu \mathrm{M}), \mathrm{H}_{2} \mathrm{O}_{2}(80 \mu \mathrm{M})$ was added, and either a full ESR spectra (Figure S3a) or the time course of the EPR signal (Figure S3b-e) was recorded. The duration of the recordings were $10 \mathrm{~min}$ for sample A, and $1 \mathrm{~min}$ for the time course of the EPR signals (samples b-e). Sample d (Figure S3d) contained graphene oxide $\left(5 \times 10^{-5} \mathrm{mg} / \mathrm{ml}\right)$, and sample e (Figure S3e) contained RGO $\left(5 \times 10^{-5} \mathrm{mg} / \mathrm{ml}\right)$.

For the study, a JEOL-RE1X spectrometer at $25{ }^{\circ} \mathrm{C}$ outfitted with a gas-permeable Teflon tubing ( $0.8 \mathrm{~mm}$ i.d., $0.013 \mathrm{~mm}$ thickness) obtained from Alpha Wire Corp. (Elizabeth, NJ) was utilized. The tube (approximately $8 \mathrm{~cm}$ in length) was filled with $70 \mu \mathrm{L}$ of the mixed sample, folded into quarters, and placed in an opened $3.0 \mathrm{~mm}$ i.d. EPR quartz tube. The etoposide phenoxyl radical spectra were recorded under following conditions: $3350 \mathrm{G}$, center field; $50 \mathrm{G}$, sweep width; $0.5 \mathrm{G}$, field modulation; $10 \mathrm{~mW}$, microwave power; $0.03 \mathrm{~s}$, time constant; 2 min, timescane (sample a). The time course of etoposide radical EPR signals was obtained by repeated scanning of the field $(1.0 \mathrm{G}$, sweep width; $3350 \mathrm{G}$, center field; 8 min, timescane) that corresponded to part of the EPR signal (samples b-e).

\section{Polyacrylamide Gel Electrophoresis (PAGE)}

Four samples were analyzed using gel electrophoresis, which included: a control for horseradish peroxidase (HRP, $1.1 \mathrm{mg}$ ) (around $44 \mathrm{kDa}$ ) without hydrogen peroxide $\left(\mathrm{H}_{2} \mathrm{O}_{2}\right)$, $\mathrm{HRP}\left(1.1 \mathrm{mg}\right.$ ) incubated for three hours in the presence of $\mathrm{H}_{2} \mathrm{O}_{2}$ (final concentration of 40 $\mu \mathrm{M} \mathrm{H}_{2} \mathrm{O}_{2}$ added every 1 hour), and HRP (1.1 mg each) incubated with graphene oxide or reduced graphene oxide (RGO) for three hours in the presence of $\mathrm{H}_{2} \mathrm{O}_{2}$ (final concentration of $40 \mu \mathrm{M} \mathrm{H}_{2} \mathrm{O}_{2}$ added every 1 hour). Samples were separated by sodium dodecyl sulfate (SDS) PAGE in Tris-glycine buffer. The running gel contained $10 \%$ acrylamide, $0.375 \mathrm{mM}$ 
tris- $\mathrm{HCl}$ buffer (pH 8.8), $0.1 \%$ SDS; the stacking gel contained $4 \%$ acrylamide, $0.125 \mathrm{mM}$ tris- $\mathrm{HCl}$ buffer ( $\mathrm{pH} 6.8$ ), $0.1 \%$ SDS. Gels were polymerized by the addition of $0.1 \%$ ammonium persulfate and $0.1 \%$ TEMED. Running buffer included $250 \mathrm{mM}$ tris, $250 \mathrm{mM}$ glycine, $0.1 \%$ SDS. Samples were diluted in the loading buffer containing $0.125 \mathrm{mM}$ tris$\mathrm{HCl}(\mathrm{pH} 6.8), 1 \%$ SDS and boiled for $5 \mathrm{~min}$. Electrophoresis was run at a constant voltage of $130 \mathrm{~V}$. Gels were stained by a SilverSNAP kit according to the manufacturer's manual.

\section{Enzymatic Kinetic Studies}

Amplex Red was employed to measure the concentration of the substrate, $\mathrm{H}_{2} \mathrm{O}_{2}$, as a function of time for a constant concentration of $\operatorname{HRP}\left(0.390 \mathrm{mg} \mathrm{mL}^{-1}\right)$ incubated with graphene oxide (graphene oxide-active). At time $\mathrm{t}=0,4 \mu \mathrm{L}$ of $0.1 \mathrm{M} \mathrm{H}_{2} \mathrm{O}_{2}$ was added to the sample for a final concentration of $40 \mu \mathrm{M}$. At 5 minute time intervals (for 1 hour), a $249 \mu \mathrm{L}$ aliquot of sample and $1 \mu \mathrm{L}$ of $10 \mathrm{mM}$ Amplex Red was gently mixed, and the UV-Vis spectrum of the sample was taken with $1 \times$ PBS utilized as the background. Figure $5 \mathrm{~d}$ contained the resulting concentration vs. time plots for graphene oxide-active; the data was fitted with an exponential decay plot.

\section{Fourier Transform - Infrared Spectroscopy}

Graphene oxide, RGO, and hRGO were isolated using TefSep Teflon laminated filters $(0.22$ $\mu \mathrm{m}$ hole size). Each sample was mixed with $\mathrm{KBr}$ and ground into a fine powder using a mortar and pestle. A KBr pellet was formed from the powder using a press, and the transmittance spectrum of the pellet was taken employing an Avatar 360 FT-IR.

\section{Gas Chromatography - Mass Spectrometry (GC-MS)}

Approximately $2 \mu \mathrm{L}$ of sample headspace (total headspace volume: $5 \mathrm{~mL}$ ) was injected into a Shimadzu QP5050A GC-MS unit equipt with an XTI-F capillary column by sampling through the septum of one of the five vials (graphene oxide-active, graphene oxide-control I, graphene oxide-control II, graphene oxide-control III, and RGO-active) on day 0 and 10 of the oxidation study. A basic temperature program was performed, starting at $100{ }^{\circ} \mathrm{C}$ held for one minute, followed by temperature ramping at a rate of $10{ }^{\circ} \mathrm{C} \mathrm{min}^{-1}$ until a maximum temperature of $325^{\circ} \mathrm{C}$ was achieved and held for an additional 10 minutes.

\section{Fabrication and Measurement of Solution- and Back-Gated RGO and hRGO Field-effect Transistors}

Field-effect transistors (FETs) were fabricated using standard photolithography process on $\mathrm{Si} / \mathrm{SiO}_{2}$ (oxide thickness $=200 \mathrm{~nm}$ ). The Ti/Au metal contacts $(\mathrm{Ti} / \mathrm{Au}=30 / 100 \mathrm{~nm}$ ) were deposited by electron beam evaporation. Individual graphene flakes were dielectrophretically deposited onto interdigitated electrodes at a frequency of $300 \mathrm{kHz}$ and an a.c field of $1.6 \mathrm{MV} \mathrm{m}^{-1,52}$ and devices were annealed in vacuum at $180^{\circ} \mathrm{C}$ for 2 hours. The Si chips with graphene flakes were wire-bonded and packaged in a 40-pin ceramic dualinline package. For backgate measurements, the Si substrate served as gate electrode. The electrical performance of the device was measured using two source measuring units (Keithley 2400). The gate potential was swept from $-85 \mathrm{~V}$ to $+85 \mathrm{~V}$ with a constant source drain voltage $\left(\mathrm{V}_{\mathrm{ds}}\right)$ of $50 \mathrm{mV}$ or from $-20 \mathrm{~V}$ to $+20 \mathrm{~V}$ with a constant source drain voltage $\left(\mathrm{V}_{\mathrm{ds}}\right)$ of $10 \mathrm{mV}$.

For solution-gated measurements, a liquid gate potential was applied to $\mathrm{Ag} / \mathrm{AgCl}(3 \mathrm{M} \mathrm{NaCl})$ reference electrode. Epoxy resin was used to prevent direct contact between metal electrode and electrolyte, leaving active graphene area exposed to electrolyte solution. A small polymer chamber was placed on the chip and sealed with epoxy to hold a small volume (a few $\mathrm{ml}$ ) of the electrolyte. Solution gate measurements were performed in $10 \mathrm{mM} \mathrm{KCl} / 10$ 
mM PBS $(\mathrm{pH}=7)$, and the gate voltage was swept from $-0.75 \mathrm{~V}$ to $+0.75 \mathrm{~V}$ with the $\mathrm{V}_{\mathrm{ds}}$ kept constant at $10 \mathrm{mV}$.

\section{Molecular Modeling}

HRP was docked to different chemical structures of RGO and graphene oxide. 3D structures of RGO and graphene oxide sheets with dimensions of $3 \mathrm{~nm}$ were generated using SketchEI molecular editing tool provided by the VegaZZ software package.53 Where indicated, edges of RGO were modified to contain both carboxyl and carbonyl groups. In the case of graphene oxide, the basal plane always contained epoxide and hydroxyl groups, and the edges had a combination of carbonyl, carboxyl, lactol, and phenolic groups in accordance with previous work.54, 55 Using AutoDock Vina software, ${ }^{56}$ docking of HRP's X-ray crystal structure (PDB ID: 1H5A, chain A) to both RGO and graphene oxide sheets was performed as described previously. ${ }^{24} \mathrm{~A}$ grid box with dimensions of $120 \AA$ in the $\mathrm{x}, \mathrm{y}$, and $\mathrm{z}$ directions was used with the center of the box placed at the center of the protein molecule. The resulting 9 graphene ligand bound poses were further analyzed to find the most preferred binding pose in each case. The preferred binding pose was defined as the pose that has the minimum energy with the maximum number of poses clustered in that site.

\section{Supplementary Material}

Refer to Web version on PubMed Central for supplementary material.

\section{Acknowledgments}

This work was supported by NIEHS R01ES019304, NIOSH 0H008282, and the $7^{\text {th }}$ Framework Program of the European Commission (EC-FP7-NANOMMUNE-214281). G.P.K. acknowledges an EPA STAR Graduate Fellowship FP-91713801.

\section{REFERENCES AND NOTES}

1. Geim AK, Novoselov KS. The Rise of Graphene. Nat. Mater. 2007; 6:183-191. [PubMed: 17330084]

2. Zhu Y, Murali S, Cai W, Li X, Suk JW, Potts JR, Ruoff RS. Graphene and Graphene Oxide: Synthesis, Properties, and Applications. Advanced Materials. 2010; 22:3906-3924. [PubMed: 20706983]

3. Lee C, Wei X, Kysar JW, Hone J. Measurement of the Elastic Properties and Intrinsic Strength of Monolayer Graphene. Science. 2008; 321:385-388. [PubMed: 18635798]

4. Geim AK. Graphene: Status and Prospects. Science. 2009; 324:1530-1534. [PubMed: 19541989]

5. Allen MJ, Tung VC, Kaner RB. Honeycomb Carbon: A Review of Graphene. Chem. Rev. 2010; 110:132-145. [PubMed: 19610631]

6. Kauffman DR, Star A. Graphene Versus Carbon Nanotubes for Chemical Sensor and Fuel Cell Applications. Analyst. 2010; 135:2790-2797. [PubMed: 20733998]

7. Dreyer DR, Park S, Bielawski CW, Ruoff RS. The Chemistry of Graphene Oxide. Chem. Soc. Rev. 2010; 39:228-240. [PubMed: 20023850]

8. Park S, Ruoff RS. Chemical Methods for the Production of Graphenes. Nat. Nanotechnol. 2009; 4:217-224. [PubMed: 19350030]

9. Stankovich S, Dikin DA, Dommett GHB, Kohlhaas KM, Zimney EJ, Stach EA, Piner RD, Nguyen ST, Ruoff RS. Graphene-Based Composite Materials. Nature. 2006; 442:282-286. [PubMed: 16855586]

10. Tung VC, Allen MJ, Yang Y, Kaner RB. High-Throughput Solution Processing of Large-Scale Graphene. Nat. Nanotechnol. 2009; 4:25-29. [PubMed: 19119278] 
11. Schniepp HC, Li J-L, McAllister MJ, Sai H, Herrera-Alonso M, Adamson DH, Prud'homme RK, Car R, Saville DA, Aksay IA. Functionalized Single Graphene Sheets Derived from Splitting Graphite Oxide. J. Phys. Chem. B. 2006; 110:8535-8539. [PubMed: 16640401]

12. McAllister MJ, Li J-L, Adamson DH, Schniepp HC, Abdala AA, Liu J, Herrera-Alonso M, Milius DL, Car R, Prud'homme RK, et al. Single Sheet Functionalized Graphene by Oxidation and Thermal Expansion of Graphite. Chem. Mater. 2007; 19:4396-4404.

13. Dreyer DR, Ruoff RS, Bielawski CW. From Conception to Realization: An Historial Account of Graphene and Some Perspectives for Its Future. Angewandte Chemie International Edition. 2010; 49:9336-9344.

14. Sun X, Liu Z, Welsher K, Robinson J, Goodwin A, Zaric S, Dai H. Nano-Graphene Oxide for Cellular Imaging and Drug Delivery. Nano Research. 2008; 1:203-212. [PubMed: 20216934]

15. Dikin DA, Stankovich S, Zimney EJ, Piner RD, Dommett GHB, Evmenenko G, Nguyen ST, Ruoff RS. Preparation and Characterization of Graphene Oxide Paper. Nature. 2007; 448:457-460. [PubMed: 17653188]

16. Li S-S, Tu K-H, Lin C-C, Chen C-W, Chhowalla M. Solution-Processable Graphene Oxide as an Efficient Hole Transport Layer in Polymer Solar Cells. ACS Nano. 2010; 4:3169-3174. [PubMed: 20481512]

17. Robinson JT, Perkins FK, Snow ES, Wei Z, Sheehan PE. Reduced Graphene Oxide Molecular Sensors. Nano Lett. 2008; 8:3137-3140. [PubMed: 18763832]

18. Zhou M, Zhai YM, Dong SJ. Electrochemical Sensing and Biosensing Platform Based on Chemically Reduced Graphene Oxide. Anal. Chem. 2009; 81:5603-5613. [PubMed: 19522529]

19. Li D, Mueller MB, Gilje S, Kaner RB, Wallace GG. Processable Aqueous Dispersions of Graphene Nanosheets. Nat. Nanotechnol. 2008; 3:101-105. [PubMed: 18654470]

20. Liu L, Ryu S, Tomasik MR, Stolyarova E, Jung N, Hybertsen MS, Steigerwald ML, Brus LE, Flynn GW. Graphene Oxidation: Thickness-Dependent Etching and Strong Chemical Doping. Nano Lett. 2008; 8:1965-1970. [PubMed: 18563942]

21. Tapaszto L, Dobrik G, Lambin P, Biro LP. Tailoring the Atomic Structure of Graphene Nanoribbons by Scanning Tunnelling Microscope Lithography. Nat. Nanotechnol. 2008; 3:397401. [PubMed: 18654562]

22. Li X, Wang X, Zhang L, Lee S, Dai H. Chemically Derived, Ultrasmooth Graphene Nanoribbon Semiconductors. Science. 2008; 319:1229-1232. [PubMed: 18218865]

23. Allen BL, Kichambare PD, Gou P, Vlasova II, Kapralov AA, Konduru N, Kagan VE, Star A. Biodegradation of Single-Walled Carbon Nanotubes through Enzymatic Catalysis. Nano Lett. 2008; 8:3899-3903. [PubMed: 18954125]

24. Allen BL, Kotchey GP, Chen Y, Yanamala NVK, Klein-Seetharaman J, Kagan VE, Star A. Mechanistic Investigations of Horseradish Peroxidase-Catalyzed Degradation of Single-Walled Carbon Nanotubes. J. Am. Chem. Soc. 2009; 131:17194-17205. [PubMed: 19891488]

25. Kagan VE, Konduru NV, Feng W, Allen BL, Conroy J, Volkov Y, Vlasova II, Belikova NA, Yanamala N, Kapralov A, et al. Carbon Nanotubes Degraded by Neutrophil Myeloperoxidase Induce Less Pulmonary Inflammation. Nat Nano. 2010; 5:354-359.

26. Dresselhaus MS, Jorio A, Hofmann M, Dresselhaus G, Saito R. Perspectives on Carbon Nanotubes and Graphene Raman Spectroscopy. Nano Lett. 2010; 10:751-758. [PubMed: 20085345]

27. Gorris HH, Walt DR. Mechanistic Aspects of Horseradish Peroxidase Elucidated through SingleMolecule Studies. J. Am. Chem. Soc. 2009; 131:6277-6282. [PubMed: 19338338]

28. Welinder KG. Amino Acid Sequence Studies of Horseradish Peroxidase. Eur. J. Biochem. 1979; 96:483-502. [PubMed: 38113]

29. Qian SY, Chen YR, Deterding LJ, Fann YC, Chignell CF, Tomer KB, Mason RP. Identification of Protein-Derived Tyrosyl Radical in the Reaction of Cytochrome $\mathrm{C}$ and Hydrogen Peroxide: Characterization by Esr Spin-Trapping, Hplc and Ms. Biochem. J. 2002; 363:281-288. [PubMed: 11931655]

30. Detweiler CD, Lardinois OM, Deterding LJ, de Montellano PRO, Tomer KB, Mason RP. Identification of the Myoglobin Tyrosyl Radical by Immuno-Spin Trapping and Its Dimerization. Free Radical Biology and Medicine. 2005; 38:969-976. [PubMed: 15749393] 
31. Ehrenshaft M, Mason RP. Protein Radical Formation on Thyroid Peroxidase During Turnover as Detected by Immuno-Spin Trapping. Free Radical Biology and Medicine. 2006; 41:422-430. [PubMed: 16843823]

32. Trott O, Olson AJ. Autodock Vina: Improving the Speed and Accuracy of Docking with a New Scoring Function, Efficient Optimization and Multithreading. J. Comput. Chem. 2010; 31:455461. [PubMed: 19499576]

33. Filizola M, Loew GH. Role of Protein Environment in Horseradish Peroxidase Compound I Formation: Molecular Dynamics Simulations of Horseradish Peroxidase-Hooh Complex. J. Am. Chem. Soc. 2000; 122:18-25.

34. Tuynman A, Spelberg JL, Kooter IM, Schoemaker HE, Wever R. Enantioselective Epoxidation and Carbon-Carbon Bond Cleavage Catalyzed by Coprinus Cinereus Peroxidase and Myeloperoxidase. J. Biol. Chem. 2000; 275:3025-3030. [PubMed: 10652281]

35. Ortiz de Montellano PR, Grab LA. Cooxidation of Styrene by Horseradish Peroxidase and Phenols: A Biochemical Model for Protein-Mediated Cooxidation. Biochemistry. 1987; 26:53105314. [PubMed: 2823878]

36. Novoselov KS, Geim AK, Morozov SV, Jiang D, Katsnelson MI, Grigorieva IV, Dubonos SV, Firsov AA. Two-Dimensional Gas of Massless Dirac Fermions in Graphene. Nature. 2005; 438:197-200. [PubMed: 16281030]

37. Meric I, Han MY, Young AF, Ozyilmaz B, Kim P, Shepard KL. Current Saturation in ZeroBandgap, Top-Gated Graphene Field-Effect Transistors. Nat. Nanotechnol. 2008; 3:654-659. [PubMed: 18989330]

38. Nakada K, Fujita M, Dresselhaus G, Dresselhaus MS. Edge State in Graphene Ribbons: Nanometer Size Effect and Edge Shape Dependence. Phys. Rev. B: Condens. Matter Mater. Phys. 1996; 54:17954.

39. Son Y-W, Cohen ML, Louie SG. Energy Gaps in Graphene Nanoribbons. Phys. Rev. Lett. 2006; 97:216803. [PubMed: 17155765]

40. Barone V, Hod O, Scuseria GE. Electronic Structure and Stability of Semiconducting Graphene Nanoribbons. Nano Lett. 2006; 6:2748-2754. [PubMed: 17163699]

41. Bai J, Zhong X, Jiang S, Huang Y, Duan X. Graphene Nanomesh. Nat Nano. 2010; 5:190-194.

42. Kim M, Safron NS, Han E, Arnold MS, Gopalan P. Fabrication and Characterization of LargeArea, Semiconducting Nanoperforated Graphene Materials. Nano Lett. 2010; 10:1125-1131. [PubMed: 20192229]

43. Liu H, Ryu S, Chen Z, Steigerwald ML, Nuckolls C, Brus LE. Photochemical Reactivity of Graphene. J. Am. Chem. Soc. 2009; 131:17099-17101. [PubMed: 19902927]

44. Huang JY, Qi L, Li J. In Situ Imaging of Layer-by-Layer Sublimation of Suspended Graphene. Nano Research. 2010; 3:43-50.

45. Bieri M, Treier M, Cai J, Ait-Mansour K, Ruffieux P, Groning O, Groning P, Kastler M, Rieger R, Feng X, et al. Porous Graphenes: Two-Dimensional Polymer Synthesis with Atomic Precision. Chem. Commun. 2009:6919-6921.

46. Chen F, Qing Q, Xia J, Li J, Tao N. Electrochemical Gate-Controlled Charge Transport in Graphene in Ionic Liquid and Aqueous Solution. J. Am. Chem. Soc. 2009; 131:9908-9909. [PubMed: 19572712]

47. Eda G, Fanchini G, Chhowalla M. Large-Area Ultrathin Films of Reduced Graphene Oxide as a Transparent and Flexible Electronic Material. Nat. Nanotechnol. 2008; 3:270-274. [PubMed: 18654522]

48. Jung I, Dikin DA, Piner RD, Ruoff RS. Tunable Electrical Conductivity of Individual Graphene Oxide Sheets Reduced at "Low" Temperatures. Nano Lett. 2008; 8:4283-4287. [PubMed: 19367929]

49. Joung D, Chunder A, Zhai L, Khondaker SI. High Yield Fabrication of Chemically Reduced Graphene Oxide Field Effect Transistors by Dielectrophoresis. Nanotechnology. 2010; 21

50. Salas EC, Sun Z, Lüttge A, Tour JM. Reduction of Graphene Oxide Via Bacterial Respiration. ACS Nano. 2010; 4:4852-4856. [PubMed: 20731460] 
51. Kovtyukhova NI, Ollivier PJ, Martin BR, Mallouk TE, Chizhik SA, Buzaneva EV, Gorchinskiy AD. Layer-by-Layer Assembly of Ultrathin Composite Films from Micron-Sized Graphite Oxide Sheets and Polycations. Chem. Mater. 1999; 11:771-778.

52. Vijayaraghavan A, Sciascia C, Dehm S, Lombardo A, Bonetti A, Ferrari AC, Krupke R. Dielectrophoretic Assembly of High-Density Arrays of Individual Graphene Devices for Rapid Screening. ACS Nano. 2009; 3:1729-1734.

53. Pedretti A, Villa L, Vistoli G. Vega--an Open Platform to Develop Chemo-Bio-Informatics Applications, Using Plug-in Architecture and Script Programming. Journal of computer-aided molecular design. 2004; 18:167-173. [PubMed: 15368917]

54. Lerf A, He H, Forster M, Klinowski J. Structure of Graphite Oxide Revisited. J. Phys. Chem. B. 1998; 102:4477-4482.

55. Casabianca LB, Shaibat MA, Cai WW, Park S, Piner R, Ruoff RS, Ishii Y. Nmr-Based Structural Modeling of Graphite Oxide Using Multidimensional 13c Solid-State Nmr and Ab Initio Chemical Shift Calculations. J. Am. Chem. Soc. 2010; 132:5672-5676. [PubMed: 20359218]

56. Trott O, Olson AJ. Software News and Update Autodock Vina: Improving the Speed and Accuracy of Docking with a New Scoring Function, Efficient Optimization, and Multithreading. J. Comput. Chem. 2010; 31:455-461. [PubMed: 19499576] 


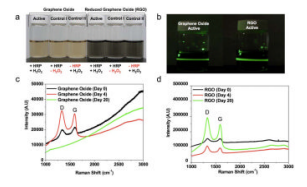

Figure 1.

(a) Sample vials for the graphene oxide and reduced graphene oxide (RGO) enzymatic oxidation experiment. (b) The Tyndall scattering effect confirmed that the dispersions that consist of either graphene oxide or RGO with HRP (at day 0 of the oxidation process) were colloids. Raman spectra depicting (c) graphene oxide and (d) RGO after days 0 (black), 4 (red), and 20 (green) of incubation with horseradish peroxidase (HRP)/ $\mathrm{H}_{2} \mathrm{O}_{2}$. The $\mathrm{D}$ and $\mathrm{G}$ bands are marked on the spectrum. 


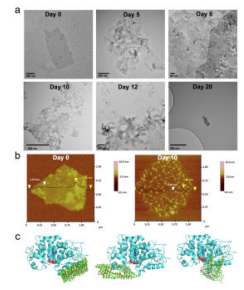

Figure 2.

(a) Transmission electron microscopy (TEM) micrographs of graphene oxide after $0,5,8$, 10,12 , and 20 days of incubation with horseradish peroxidase (HRP) and $40 \mu \mathrm{M}$ hydrogen peroxide $\left(\mathrm{H}_{2} \mathrm{O}_{2}\right)$. Arrows indicate hole formation in the basal plane at day 8. (b) Atomic force microscopy (AFM) images with section analysis of graphene oxide with HRP at day 0 (left) and holey graphene oxide at day 10 (right). Graphene oxide with HRP has a sheet height of $5.37 \mathrm{~nm}$ and $9.81 \mathrm{~nm}$. Holey graphene oxide has a sheet height of $1.10 \mathrm{~nm}$, and the holes were authentic at a height of $0.01 \mathrm{~nm}$. (c) Binding poses of HRP on (from left to right) graphene oxide, holey graphene oxide, and a small sheet of graphene oxide calculated using molecular docking studies (AutoDock Vina). 


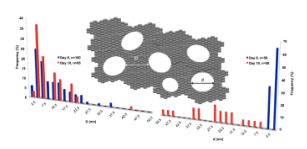

Figure 3.

Histograms of neck width (D) and hole diameter (d) on days 8 and 10 of the oxidation process as measured from TEM micrographs. The cartoon insert illustrates the definitions of neck width and hole diameter. 

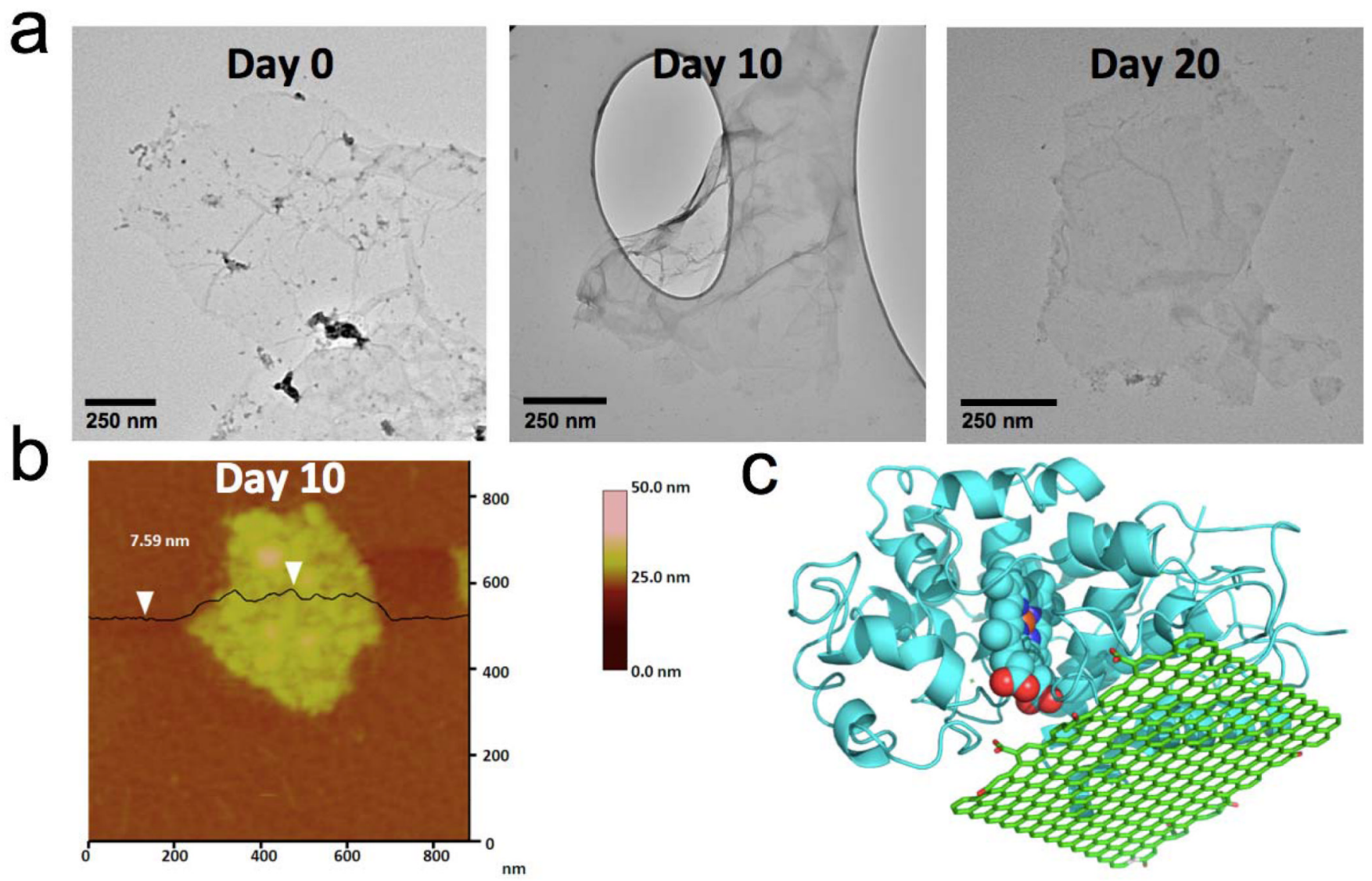

Figure 4.

(a) Transmission electron microscopy (TEM) micrographs of reduced graphene oxide (RGO) after 0, 10, and 20 days of incubation with horseradish peroxidase (HRP) and $40 \mu \mathrm{M}$ hydrogen peroxide $\left(\mathrm{H}_{2} \mathrm{O}_{2}\right)$. (b) Atomic force microscopy (AFM) images with section analysis of RGO with HRP at day 10. RGO with HRP has a sheet height of $7.59 \mathrm{~nm}$. (c) Binding poses of HRP on RGO calculated using molecular docking studies (AutoDock Vina). 


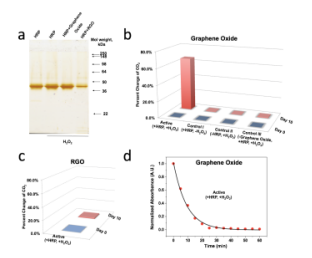

Figure 5.

(a) Sodium dodecyl sulfate polyacrylamide gel electrophoresis (SDS-PAGE) with silver staining. The gel contained a control for horseradish peroxidase (HRP, around $44 \mathrm{kDa}$ ) without hydrogen peroxide $\left(\mathrm{H}_{2} \mathrm{O}_{2}\right)$, HRP incubated for three hours in the presence of $\mathrm{H}_{2} \mathrm{O}_{2}$ (final concentration of $40 \mu \mathrm{M} \mathrm{H}_{2} \mathrm{O}_{2}$ added every $1 \mathrm{~h}$ ), and $\mathrm{HRP}$ incubated with graphene oxide or reduced graphene oxide (RGO) for three hours in the presence of $\mathrm{H}_{2} \mathrm{O}_{2}$ (final concentration of $40 \mu \mathrm{M} \mathrm{H}_{2} \mathrm{O}_{2}$ added every $1 \mathrm{~h}$ ). A mass of $1.1 \mathrm{mg}$ of HRP was utilized per test. (b,c) Relative increase in headspace $\mathrm{CO}_{2}$ concentration as measured by GC-MS for day 0 and 10 for (b) graphene oxide-active, control I $\left(-\mathrm{H}_{2} \mathrm{O}_{2}\right)$, control II $(-\mathrm{HRP})$, control III (graphene oxide), and (c) RGO-active. It was determined that the $\mathrm{CO}_{2}$ concentrations in the headspace of the sample vials increased by $65 \%$ for graphene oxide-active, $<1 \%$ for graphene oxide-control I, graphene oxide-control II, and graphene oxide-control III, and $2 \%$ for RGO-active. (d) Examination of the enzymatic kinetics for the graphene oxide-active sample employing an Amplex Red assay, where the absorbance of resorufin, which was directly proportional to $\mathrm{H}_{2} \mathrm{O}_{2}$ concentration, was measured at 5-minute time intervals for 1 hour. The assay indicated that nearly all of the $\mathrm{H}_{2} \mathrm{O}_{2}$ was consumed over the first 30minutes of analysis as graphene oxide was oxidized. 

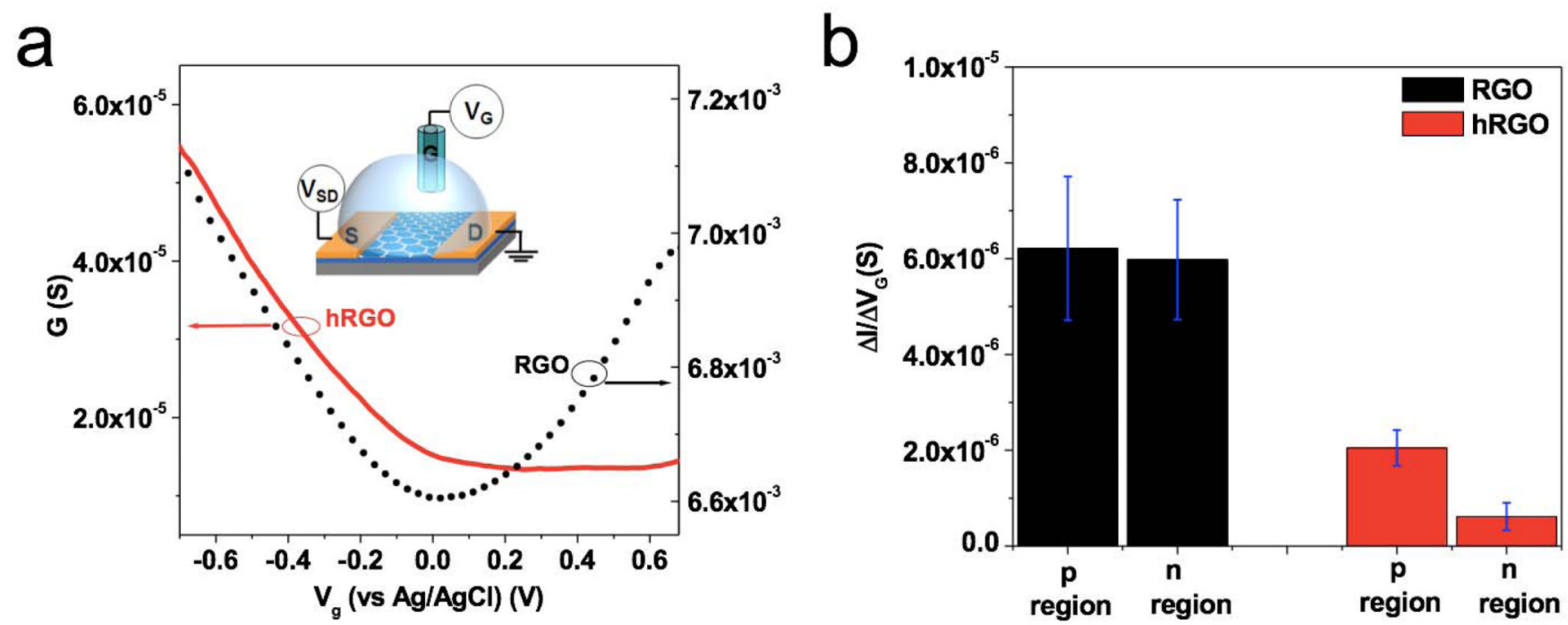

Figure 6.

(a) Conductivity versus potential (liquid gate) plot for reduced graphene oxide (RGO, black circles) and holey reduced graphene oxide (hRGO, solid red line). The measurements were recorded in $10 \mathrm{mM} \mathrm{KCl} / 10 \mathrm{mM}$ PBS (pH 7) at a constant drain-source voltage of $10 \mathrm{mV}$. The inset represents a schematic of the experimental setup. (b) Comparison of transconductance $\left(\Delta \mathrm{I} / \Delta \mathrm{V}_{\mathrm{g}}\right)$ values of $\mathrm{n}$ and $\mathrm{p}$ region of 12 different $\mathrm{RGO}$ and hRGO FET devices (6 devices each). 